\title{
"Real-life" Efficacy and Safety Aspects of 4-Year Omalizumab Treatment for Asthma
}

\author{
Mona Al-Ahmad ${ }^{a}$ b Nermina Arifhodzic ${ }^{b} \quad$ Jasmina Nurkic $^{b} \quad$ Ahmed Maher $^{b}$ \\ Tito Rodriguez-Bouza $^{\mathrm{b}}$ Nasser Al-Ahmed ${ }^{\mathrm{b}}$ Ali Sadek $^{\mathrm{c}}$ Edin Jusufovic ${ }^{\mathrm{d}}$ \\ ${ }^{a}$ Department of Microbiology, Faculty of Medicine, Kuwait University, Kuwait, Kuwait; \\ ${ }^{b}$ Al-Rashed Allergy Center, Ministry of Health, Kuwait, Kuwait; \\ 'National Center of Health Information, Ministry of Health, Kuwait, Kuwait; \\ ${ }^{d}$ Cathedra for Internal Medicine Department, Faculty of Medicine, University of Tuzla, Tuzla, Bosnia-Herzegovina
}

\section{Significance of the Study}

- In this study, the long-term efficacy and safety of omalizumab therapy in asthma were evaluated in a real-life setting. Omalizumab therapy resulted in better asthma control, and was effective and well tolerated as an add-on therapy for patients with moderate-to-severe asthma.

\section{Keywords}

Omalizumab · Asthma · Long-term therapy · Efficacy · Safety

\begin{abstract}
Objective: To evaluate the long-term efficacy and safety of omalizumab in asthma in a real-life setting. Subjects and Methods: This 4-year observational study included 65 patients treated with omalizumab during clinic visits; treatment response was rated as excellent, good, and partial based on a modified physician's Global Evaluation of Treatment Effectiveness (mGETE) scale of emergency room visits (ERV), hospitalization, use of oral corticosteroids, inhaled corticosteroid (ICS)/long-acting $\beta$-agonist (LABA) dose, and short-acting $\beta$-agonist rescue. The following tests were done: forced expiratory volume in $1 \mathrm{~s}\left(\mathrm{FEV}_{1}\right)$ and the asthma control test (ACT). Measurements were performed 1 month before therapy and at 16 weeks, 1 year, and 4 years of treatment. Statistical analyses were done using the Wilcoxon
\end{abstract}

\begin{tabular}{ll}
\hline KARGER & $\begin{array}{l}\text { ( 2018 The Author(s) Karger } \\
\text { Published by S. Karger AG, Basel }\end{array}$ \\
E-Mail karger@karger.com & $\begin{array}{l}\text { This is an Open Access article licensed under the Creative Commons } \\
\text { Attribution-NonCommercial-4.0 International License (CC BY-NC) } \\
\text { (http://www.karger.com/Services/OpenAccessLicense), applicable to } \\
\text { the online version of the article only. Usage and distribution for com- } \\
\text { mercial purposes requires written permission. }\end{array}$
\end{tabular}

signed-rank test, Spearman rank correlation, and McNemar $X^{2}$ test. Results: The dropout rate was 15 (18.5\%): 8 nonresponders (10.0\%); 2 patients died (2.5\%), and 5 were lost to follow-up (6.25\%). Treatment response was excellent in 35 (53.8\%); good in 23 (35.4\%), and partial in 7 patients (10.8\%). The number of excellent responders increased from 35 (53.8\%) at 16 weeks to $48(73.8 \%)$ at the 4 -year follow-up. The number of patients who did not require ERV improved from 0 to $59(90.8 \%)$, and the lowest rate of hospitalization was 1 in year $4(p<0.001)$; patients who did not require courses of oral corticosteroids improved from 0 to 54 (83\%). ICS/LABA dose significantly reduced from $65(100 \%)$ to $25(38.5 \%)$ after 4 years of treatment $(p<0.001)$; ACT scores significantly increased from $15 \pm 3$ at baseline to $23 \pm 3(p<0.001)$ and FEV 1 level from $55.6 \pm 10.6$ to $76.63 \pm 10.34$ at year 4 . Conclusion: In this study, omalizumab therapy resulted in better asthma control, and was effective and well tolerated as an add-on therapy for patients with moderate-to-severe asthma.

(C) 2018 The Author(s)

Published by S. Karger AG, Basel

Dr. Mona Al-Ahmad

Department of Microbiology

Faculty of Medicine, Kuwait University

PO Box 24923, Safat 13110 (Kuwait)

E-Mail Alahmadm@ @sc.edu.kw 


\section{Introduction}

Despite remarkable advances in the understanding of asthma pathogenesis, diagnosis, and availability of medication [1], there is a group of asthmatic patients who are still poorly controlled despite receiving the maximal available treatment $[1,2]$. Previous studies reported that the disease pathogenesis of $50-80 \%$ of difficult-to-treat asthma patients involves an IgE-mediated mechanism that triggers allergic inflammation $[3,4]$. Omalizumab (Xolair, Novartis) is the first biosynthetic recombinant humanized monoclonal antibody to directly target the IgE molecule [1]. It inhibits the binding of IgE to high-affinity receptors on effector cells and thereby interrupts the inflammatory cascade that is involved in the pathogenesis of allergic asthma $[4,5]$. Since its approval by the Food and Drug Administration (FDA), omalizumab has been listed in the updated guidelines as an add-on treatment for moderateto-severe allergic asthma that is poorly controlled by intensive, guideline-based therapy [6]. In September 2008, it was licensed in Kuwait. To date, there has been a wide range of double-blind, placebo-controlled trials that demonstrated the clinical efficacy and safety of omalizumab in poorly controlled patients with moderate-to-severe asthma $[4,7,8]$. A global, postmarketing, observational study, known as the eXpeRience registry [9], evaluated the efficacy and safety of 2-year treatment with omalizumab and showed good clinical outcomes consistent with other observational real-life studies [10]. However, evidence of long-term treatment efficacy and safety is still limited [1113]. Recently, numerous observational studies [14-19] demonstrated the clinical value and safety of omalizumab up to 9 years of treatment [11]. Although in international guidelines unlimited treatment with omalizumab was recommended for responders who remain suboptimally controlled using maximal-dose inhaled corticosteroids (ICS)/ long-acting $\beta$-agonist (LABA) [5], there is still debate about the optimal omalizumab treatment duration regarding efficacy and safety [20], and early cessation resulted in the recurrence of symptoms [20]. Hence, it seems reasonable to explore this issue further. Therefore, the purpose of this study was to evaluate the efficacy and safety profile of omalizumab in a "real-life" setting in patients.

\section{Subjects and Methods}

\section{Patients}

A total of 80 poorly controlled allergic asthma patients $(\geq 12$ years of age) were referred to the Al-Rashed Allergy Center, Kuwait, for treatment with omalizumab from October 2008 to Sep- tember 2012. Inclusion criteria were availability of data from the medical records of the previous year; a history of $\geq 3$ emergency room visits (ERV) per year and/or $\geq 1$ hospitalization per year due to a severe asthma exacerbation that required bursts of systemic corticosteroids; maintenance treatment with oral steroids or treatment with $\geq 3$ oral corticosteroids per year for worsening asthma symptoms, previous treatment with a maximal dose of ICS $(\geq 1,500$ $\mu \mathrm{g} /$ day beclomethasone equivalent) and LABA, and treatment with $\geq 3$ doses of short-acting $\beta$-agonist (SABA) rescue medication per week in all; a total IgE range from $\geq 30$ to $<700 \mathrm{IU} / \mathrm{mL}$, a positive skin prick test or specific IgE to $\geq 1$ inhalant allergen(s) (included in our standard aeroallergen panel), asthma control test (ACT) scores $<20$ in the month preceding omalizumab treatment, and a mean forced expiratory volume in $1 \mathrm{~s}\left(\mathrm{FEV}_{1}\right)<70 \%$ of predicted in the previous year. Exclusion criteria were age $<12$ years, pregnancy, and uncontrolled cardiovascular disease.

Based on both inclusion and exclusion criteria, 65 of the 80 patients (22 males and 43 females) were eligible for treatment with omalizumab. The Research Ethics Committee of the Ministry of Health approved this study. Written, informed consent was obtained from all study patients prior to the start of omalizumab treatment.

\section{Study Design}

This was a real-life, observational surveillance study of the long-term efficacy and safety of omalizumab in patients treated up to 4 years. The calculated dose of omalizumab prescribed was based on the manufacturer's recommendations [21] and given once or twice monthly as subcutaneous injection(s). During clinic visit, patients were questioned about ERV, hospitalization, use of oral corticosteroids, ICS/LABA dose, and SABA rescue. They were asked to do the following tests: $\mathrm{FEV}_{1}$ and ACT, and, based on those parameters, a modified physician's Global Evaluation of Treatment Effectiveness (mGETE) was done. Accordingly, we used the following scoring system: ERV (no, $\leq 2 \times /$ year, $\geq 3 \times /$ year), number of hospitalizations (yes/no), frequency of oral corticosteroid usage during the treatment in comparison to baseline (no/ $\geq 50 \%$ reduction), mGETE (excellent, good, partial), ACT score (calculated at each visit and presented as a mean/year), $\mathrm{FEV}_{1}$ (measured every 3-4 months and presented as a mean/year), ICS/LABA dose (no, $\geq 50 \%$ reduction), and the frequency of SABA rescue medication ( $\leq 2 \times /$ week, $\geq 3 \times /$ week, daily).

The primary outcome measures included: the number of ERV, the number of hospitalizations, the frequency of oral corticosteroid usage during the treatment in comparison to baseline, and mGETE. The secondary outcome measures included: ACT score, $\mathrm{FEV}_{1}, \mathrm{ICS} / \mathrm{LABA}$ dose, and the frequency of SABA rescue medication use. mGETE, which is based on the physician-rated GETE [22], was an assessment endpoint that is based on parameters such as the number of ERV, prescriptions of oral corticosteroids, rescue medication (SABA) use, ACT, $\mathrm{FEV}_{1}$, and patient interview. A simplified modified grading system from GETE was used: excellent complete control (>75\%); good - a marked improvement (50$75 \%)$, and partial - a discernible but limited improvement in asthma $(<50 \%)$. Less-than-partial GETE indicated omalizumab nonresponse.

ACT is a reliable, 5-item questionnaire that uses a scale from 1 to 5 for each of the following questions: day/night symptoms, frequency of bronchodilator use, limitation of physical activities, and shortness of breath, with a maximum total score of 25. An ACT 
score $\geq 20$ is defined as well-controlled asthma and $\leq 15$ as poorly controlled asthma. All further visits were included in an assessment of clinical response to omalizumab treatment at baseline, 16 weeks, 1 year, and 4 years. Patients without any improvement after 16 weeks of treatment were rated as nonresponders and withdrawn from further treatment. They were not included in further evaluations. Patients were weighed to the nearest kilogram, and height was measured to the nearest centimeter during their clinic visit by a nurse. The height and weight of all patients were used to calculate the body mass index (BMI: weight in kilograms divided by height in meters squared $\left[\mathrm{kg} / \mathrm{m}^{2}\right]$ ) to determine obesity and presented as mean \pm SD.

\section{Statistical Analysis}

All data were analyzed using the Statistical Package for Social Sciences (version 22.0; IBM Corp., Armonk, NY, USA). FEV 1 and ACT were checked for accuracy and normality using the Kolmogorov-Smirnov and Shapiro-Wilk tests. Qualitative variables are expressed as numbers and percentages, and quantitative variables are expressed as means \pm SD, as well as medians and interquartile ranges. The Wilcoxon signed-rank test ( $z$-value) was used as a nonparametric test of significance for comparisons of qualitative or ordinal variables before and after treatment when the paired $t$ test was not appropriate. The McNemar $\chi^{2}$ test was used for paired comparisons of dichotomous variables. The Spearman rank correlation coefficient $(r)$ was used as a nonparametric measure of the mutual relationship between 2 nonnormally distributed quantitative or ordinal variables with the GraphPad Prism software (version 7; GraphPad Software, La Jolla, CA, USA). Differences in the Wilcoxon signed-rank test; McNemar $\chi^{2}$ test, Spearman rank correlation, and others were considered statistically significant if $p<0.05$.

\section{Results}

Of the 65 patients, $15(18.7 \%)$ dropped out: 8 (10.0\%) were considered nonresponders (due to a lack of improvement in all measurements at 16 weeks), 2 (2.5\%) died, and $5(6.25 \%)$ were lost to follow-up. The demographic characteristics of the patients are shown in Table 1 . Their mean age was $46.69 \pm 11.55$ years. Obesity was common in both genders, as determined by the calculated BMI (females: $31.16 \pm 4.82$, males: $29.48 \pm 7.09$ ). The median serum IgE level was: $320 \mathrm{IU} / \mathrm{mL}$ (range: $28-$ $1,200 \mathrm{IU} / \mathrm{mL}$ ) at baseline.

The number of excellent responders gradually increased from $35(53.8 \%)$ at 16 weeks to $48(73.8 \%)$ after 4 years of treatment. The number of patients with a partial response did not change over the treatment period (Table 2). An overall excellent response was noted in 35 patients (53.8\%), good response in 23 (35.4\%), and partial response in $7(10.8 \%)$, which was documented by reduced numbers of ERV. After 16 weeks of omalizumab treatment, $32(49.2 \%)$ patients did not require ERV, which
Table 1. Demographics and patient characteristics at baseline

\begin{tabular}{ll}
\hline Total patients & $80(100)$ \\
$\quad$ Dropouts & $15(18.7)$ \\
$\quad$ Patients evaluated & $65(81.2)$ \\
$\quad$ Males & $22(33.8)$ \\
$\quad$ Females & $43(66.2)$ \\
Age (mean \pm SD), years & $46.69 \pm 11.55$ \\
Body mass index (mean \pm SD) & \\
$\quad$ Males & $29.48 \pm 7.09$ \\
$\quad$ Females & $31.16 \pm 4.82$ \\
Moderate-to-severe asthma & $59(90.7)$ \\
Severe corticosteroid-dependent asthma & $6(9.2)$ \\
Total IgE (mean \pm SD) & $407.63 \pm 306.96$ \\
Median ACT (range) & $15(6-20)$ \\
FEV ${ }_{1}$ (mean \pm SD), \% of predicted & $55.6 \pm 10.6$ \\
Exsmokers & $6(9.2)$
\end{tabular}

Numbers (\%) of patients are shown unless indicated otherwise. $\mathrm{FEV}_{1}$, forced expiratory volume in $1 \mathrm{~s}$.

Table 2. Physician assessment of the response to omalizumab at follow-up

\begin{tabular}{lccc}
\hline Response & 16 weeks & 1 year & 4 years \\
\hline Excellent $(>75 \%)$ & $35(53.8)$ & $44(67.7)$ & $48(73.8)$ \\
Good $(50-75 \%)$ & $23(35.4)$ & $14(21.5)$ & $10(15.4)$ \\
Partial $(<50 \%)$ & $7(10.8)$ & $7(10.8)$ & $7(10.8)$ \\
$p$ value & - & 0.0003 & 0.000
\end{tabular}

Numbers (\%) of patients are shown. Response was based on a modified physician's Global Evaluation of Treatment Effectiveness. The Wilcoxon signed-rank test was used to determine statistically significant differences $(p<0.05)$ vs. values at 16 weeks.

increased to $59(90.8 \%)$ after 4 years of treatment $(p<$ 0.001 ) (Table 3). Prior to omalizumab treatment, 31 $(47.7 \%)$ patients had $\geq 1$ hospitalization(s) per year due to severe asthma exacerbation, but the rate dropped significantly $(p<0.001)$ throughout the treatment period from $5(7.7 \%)$ at 16 weeks to $3(4.6 \%)$ and $1(1.5 \%)$ at 1 year and 4 years, respectively. Because the rate of hospitalization dropped, 36 (55.4\%) patients did not require oral corticosteroids at 16 weeks, and $28(43.1 \%)$ had $>50 \%$ reduction in their oral corticosteroid use. The number of patients who did not use oral corticosteroids increased during omalizumab treatment from $36(55.4 \%)$ at 16 weeks to 51 (78.0\%) and $54(83.1 \%)$ at 1 and 4 years, respectively. Of the 6 patients who were corticosteroid dependent on a daily dose, 5 were able to stop oral corticosteroids, and 1 
Table 3. Reduction in emergency room visits, hospitalization, use of oral corticosteroids, inhaled corticosteroids (ICS)/long-acting $\beta$-agonists (LABA), and short-acting $\beta$-agonists (SABA) during treatment

\begin{tabular}{|c|c|c|c|c|}
\hline & Baseline & 16 weeks & 1 year & 4 years \\
\hline \multicolumn{5}{|c|}{ Emergency room visits } \\
\hline No visits & 0 & $32(49.2)$ & $52(80.0)$ & $59(90.8)$ \\
\hline$\leq 2 \times /$ year & - & $33(50.8)$ & $13(20.0)$ & $6(9.2)$ \\
\hline$\geq 3 \times /$ year & 65 & 0 & 0 & 0 \\
\hline Wilcoxon: $\mathrm{p}^{\dagger}$ & - & 0.000 & 0.000 & 0.000 \\
\hline \multicolumn{5}{|l|}{ Hospitalization } \\
\hline Yes & $31(47.7)$ & $5(7.7)$ & $3(4.6)$ & $1(1.5)$ \\
\hline McNemar: $\mathrm{p}^{\dagger}$ & - & 0.000 & 0.000 & 0.000 \\
\hline \multicolumn{5}{|c|}{ Oral corticosteroids } \\
\hline No & - & $36(55.4)$ & $51(78.5)$ & $54(83 \%)$ \\
\hline$\geq 50 \%$ reduction & - & $28(43.1)$ & $13(20)$ & $10(15.4)$ \\
\hline Short & $59(90.8)$ & 0 & 0 & 0 \\
\hline Daily & $6(9.2)$ & $1(1.5)$ & $1(1.5)$ & $1(1.5)$ \\
\hline Wilcoxon: $\mathrm{p}^{\dagger}$ & - & 0.000 & 0.000 & 0.000 \\
\hline \multicolumn{5}{|l|}{$I C S / L A B A$} \\
\hline Max. dose & 65 & $42(64.6)$ & $36(55.4)$ & $25(38.5)$ \\
\hline$\geq 50 \%$ reduction & - & $23(35.4)$ & $29(44.6)$ & $37(56.9)$ \\
\hline Stopped & - & $0(0)$ & $0(0.0)$ & $3(4.6)$ \\
\hline Wilcoxon: $\mathrm{p}^{\ddagger}$ & - & - & 0.014 & 0.000 \\
\hline \multicolumn{5}{|l|}{$S A B A$} \\
\hline No & - & $16(24.6)$ & $24(36.9)$ & $30(46.2)$ \\
\hline$\leq 2 \times /$ week & - & $11(16.9)$ & $14(21.5)$ & $23(35.4)$ \\
\hline$\geq 3 \times /$ week & $10(15.4)$ & $13(20)$ & $11(16.9)$ & $2(3.1)$ \\
\hline Daily & $55(84.6)$ & $25(38.5)$ & $16(24.6)$ & $10(15.4)$ \\
\hline Wilcoxon: $\mathrm{p}^{\ddagger}$ & - & - & 0.000 & 0.000 \\
\hline
\end{tabular}

Numbers (\%) of patients are shown. The Wilcoxon signedrank test or the McNemar $\chi^{2}$ test was used to determine statistically significant differences $(p<0.05)$. $p$ values were compared with values at baseline $(\dagger)$ or 16 weeks $(\ddagger)$.

reduced his daily dose of oral corticosteroids (Table 3 ). There was a significant reduction in the daily dose of ICS/ LABA throughout the treatment period in 23 (35.4\%), 29 (44.6\%), and 37 patients (56.9\%) at 16 weeks, 1 year, and 4 years, respectively $(p<0.014$ at 1 year and $p<0.001$ at 4 years). ICS/LABA was discontinued in 3 patients $(4.6 \%)$ after 4 years. At 16 weeks, 25 (38.5\%) still used SABA on a daily basis, but the number decreased significantly to 10 $(15.4 \%)$ at 4 years $(p<0.001)$ (Table 3$)$. The ACT score significantly increased at all measurement points $(p<$ 0.001 ): from $15 \pm 3$ at baseline to $21 \pm 3,22 \pm 3$, and $23 \pm$ 3 at 16 weeks, 1 year, and 4 years, respectively, and this correlated well with values of $\mathrm{FEV}_{1}$ predicted, which improved from $55.6 \%$ at baseline $(r=0.338$; $95 \%$ CI: 0.09526 -
$0.5429 ; p=0.006)$ to $70.4 \%$ at 16 weeks $(r=0.51 ; 95 \% \mathrm{CI}$ : $0.30-0.68 ; p<0.0001)$ and $76.6 \%$ at 4 years $(r=0.37 ; 95 \%$ CI: $0.1274-0.56 ; p=0.003$ ) (Fig. 1 ).

The tolerability and safety profile of omalizumab was good. None of the patients developed immediate systemic allergic reactions, but 2 (4.6\%) developed new serious comorbidity: 1 malignancy in a 40-year-old female who had been treated with omalizumab for 4 months, and liver cirrhosis in a 58-year-old male who was diagnosed during the 4 th year of omalizumab treatment, who had neither a history of alcohol abuse nor hepatitis. Additionally, 2 deaths occurred. A 45-year-old female with difficult-totreat asthma and a history of 3 near-fatal asthma exacerbations was rated as a nonresponder and died 20 days after her 4th dose of omalizumab following severe asthma exacerbation. The 2 nd case was a 73 -year-old male with ischemic heart disease and a partial response after 8 months of omalizumab therapy. He died 7 days after the last dose due to cardiorespiratory failure. Mild adverse reactions were reported in 12 patients (15\%): 5 presented with headache (6.3\%); 2 with tiredness/fatigue on the day of injection $(2.5 \%)$, and 1 had hair loss (1.3\%). Four (6.1\%) patients reported local reactions (mild pain and swelling at the site of injection).

\section{Discussion}

In this study, the rate of excellent/good clinical outcome (mGETE) was high (89.2\%) in patients treated with omalizumab, which was maintained throughout the study. This finding of excellent/good clinical outcome confirmed the results of previous clinical trials $[4,7,8]$ and observational real-life studies involving shorter durations of treatment [10]. The eXpeRience registry study [9] demonstrated a good/excellent response in $69.9 \%$ of patients after 16 weeks, and this remained stable during the 2 -year treatment period. Similar findings were reported by the PERSIST study [10] and in studies of longer $(>52$ weeks) treatment durations [14-19].

In this study, only one patient was hospitalized at the end point of evaluation. This resulted in a reduction in the rate of oral corticosteroids use at all assessment points, including 6 patients who had been steroid dependent. At 4 years, only 1 patient was still on a low (alternate day) maintenance dose $(5 \mathrm{mg})$. In contrast to our results, other studies reported a $34-57.1 \%$ decrease in the total annual corticosteroid burden, and $49 \%$ of them discontinued corticosteroid treatment after 1 year of treatment $[23,24]$.
4

Med Princ Pract

DOI: $10.1159 / 000487482$
Al-Ahmad et al. 


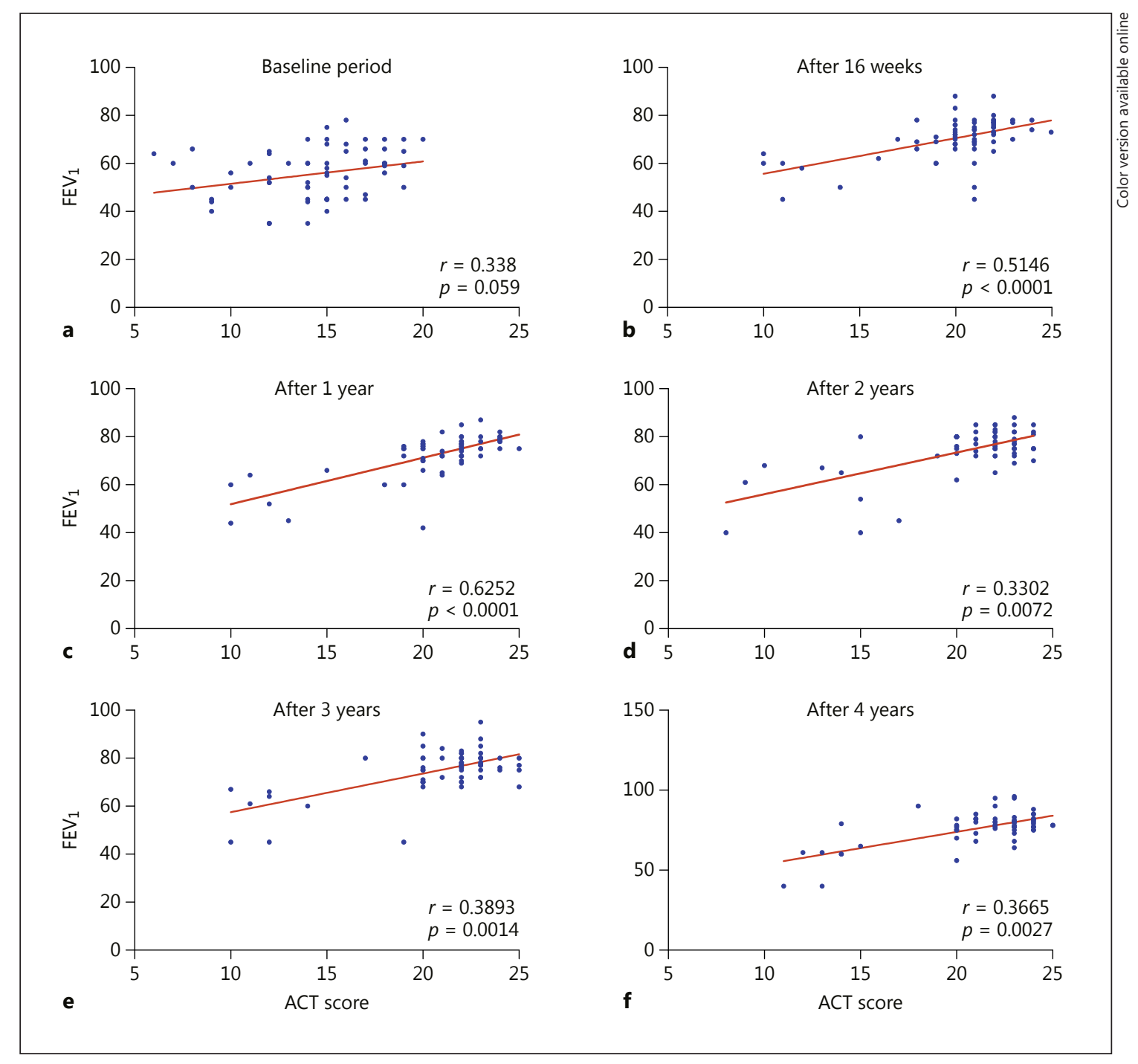

Fig. 1. Correlation between $\mathrm{FEV}_{1}$ and ACT score at different time points. a-f An increase in $\mathrm{FEV}_{1}$ was followed by a significant increase in the ACT score at all observed time points. The values of the Spearman coefficient correlation were as follows: baseline: $95 \%$ confidence interval (CI): 0.09526-0.5429; after 16 weeks: 95\% CI: 0.30280.6780; after 1 year: 95\% CI: 0.4439-0.7573; after 2 years: 95\% CI: 0.08654-0.5366; after 3 years: 95\% CI: $0.1534-$ 0.5832; and after 4 years: $95 \%$ CI: $0.1274-0.5654$.

In this study, the good clinical outcomes were reflected by a very high proportion of patients who had no ERV or had a reduced frequency of ERV for severe asthma exacerbation. Other studies showed a high number of exacerbation-free patients after 4 years of therapy [14], and reductions of $90 \%$ in the number of exacerbations and $71.3 \%$ in the number of hospitalizations after 1 year of therapy, with significant improvement in subjective and objective parameters related to good asthma control [18]. Clinical utility of long-term treatment with omalizumab has also been described in patients with severe asthma $[17,19]$. The outcome of this study confirmed those of previous studies $[6,10,14]$, in which omalizumab was given to patients in a real-life setting and provided similar benefits to those observed in clinical trials.

In this study, although $46 \%$ of the patients discontinued the use of ICS/LABA, the $(\geq 50 \%)$ reduction in the dose of ICS/LABA was significant compared with baseline. This finding confirms previous results by Tzortzaki et al. [14], in which long-term therapy with omalizumab 
was able to modify the need for a high daily ICS/LABA dose even after 4 months of treatment. Karpel et al. [8] reported a greater reduction in ICS/LABA doses for patients on omalizumab at 2 years, and in a study by Thomson and Chaudhuri [25], a higher proportion of patients were able to step down or stop ICS/LABA use at 24 weeks.

The current study showed an improvement in patients regarding SABA medication from year 1 to year 4: at 16 weeks, the percentage of patients requiring SABA on a daily basis was high, but it significantly dropped after 4 years of treatment, with even good responders feeling safer when using a nightly dose of SABA.

In this study, the ACT scores significantly increased from the very beginning and stayed above 20 until the end of the study. This finding could indicate that ACT is a good predictor of the clinical efficacy of omalizumab, which is in agreement with previous studies $[14,15,26]$. An increase in $\mathrm{FEV}_{1}$ correlated well with ACT scores at all time points. However, the mean $\mathrm{FEV}_{1}$ level did not reach $80 \%$ of predicted at year 4 , similar to the values of $75.3 \%$ at year 4 versus $58.6 \%$ at baseline reported previously by Menzella et al. [16] $(p<0.009)$. Hanania et al. [7] suggested that more studies are needed to assess the reliability of $\mathrm{FEV}_{1}$ as a predictive marker in omalizumab treatment. We noticed that the majority of our patients were obese, which might have resulted in compromised lung function. Novelli et al. [27] suggested, indeed, that the presence of some comorbidities, such as obesity, might result in limitations in lung function.

In our study, the mean age of our patients was $<50$ years. Patient age might be a possible risk for limitations in the lung function test, as suggested by Vieira et al. [26], who reported that patients $<50$ years of age had better improvement in $\mathrm{FEV}_{1}$. Our cohort was not suited to investigate the effect of age in the same way as the study by Vieira et al. [26] (Table 1). In contrast, Gouder et al. [28] did not report such findings.

In this study, long-term treatment with omalizumab was well tolerated and had a favorable safety profile, and these findings were supported by other studies $[7,15$, $17,18]$.

The number of deaths reported ( 2 cases) in the current study was lower than those reported previously $[9,29]$, which had more deaths during shorter treatment periods (1 year [9] and 2 years [29]). The deaths were thought to be unrelated to omalizumab treatment. It seems that long-term treatment with omalizumab does not increase the incidence of severe adverse events or mortality.

In this study, the $15.3 \%$ incidence of mild adverse reactions, including pain at the injection site, headache, tiredness, and hair loss, was higher than incidence rates reported in other studies $(7-12.6 \%)[29,30]$.

The limitations of this study included its open-label observational nature and the small sample size. Further limitations were that we could not identify reliable markers that could predict patient response, proper treatment periods, and the time at which treatment could be stopped.

\section{Conclusion}

In this study, omalizumab was an effective and welltolerated add-on therapy for patients with moderate-tosevere asthma. mGETE was a useful tool in evaluating long-term treatment response.

\section{References}

1 Global Initiative for Asthma (GINA) Report: Global strategy for Asthma Management and Prevention. 2010. www.ginasthma.org.

2 Khadadah M: The cost of asthma in Kuwait. Med Princ Pract 2013;22:87-91.

3 Chen HC, Huang CD, Chang E, et al: Efficacy of omalizumab $\left(\right.$ Xolair $\left.^{\circledR}\right)$ in patients with moderate to severe predominately chronic oral steroid dependent asthma in Taiwan: a retrospective, population-based database cohort study. BMC Pulm Med 2016;16:3.
4 Humbert M, Beasley R, Ayres J, et al: Benefits of omalizumab as add-on therapy in patients with severe persistent asthma who are inadequately controlled despite best available therapy (GINA 2002 step 4 treatment): INNOVATE. Allergy 2005;60:309-316.

5 Normansell R, Walker S, Milan SJ, et al: Omalizumab for asthma in adults and children. Cochrane Database Syst Rev 2014; 13:CD003559.

6 Abraham I, Alhossan A, Lee CS, et al: "Reallife" effectiveness studies of omalizumab in adult patients with severe allergic asthma: systematic review. Allergy 2016;71:593-610.
7 Hanania NA, Alpan O, Hamilos DL, et al: Omalizumab in severe allergic asthma inadequately controlled with standard therapy: a randomized trial. Ann Intern Med 2011;154: 573-582.

8 Karpel J, Massanari M, Geba GP, et al: Effectiveness of omalizumab in reducing corticosteroid burden in patients with moderate to severe persistent allergic asthma. Ann Allergy Asthma Immunol 2010;105:465-470.

9 Braunstahl GJ, Chen CW, Maykut R, et al: The eXpeRience registry: the "real-world" effectiveness of omalizumab in allergic asthma. Respir Med 2013;107:1141-1151. 
10 Brusselle G, Michils A, Louis R, et al: "Reallife" effectiveness of omalizumab in patients with severe persistent allergic asthma: the PERSIST study. Respir Med 2009;103:16331642.

-11 Menzella F, Galeone C, Formisano D, et al: Real-life efficacy of omalizumab after 9 years of follow-up. Allergy Asthma Immunol Res 2017;9:368-372.

12 Sposato B, Scalese M, Latorre M, et al: Can the response to omalizumab be influenced by treatment duration? A real-life study. Pulm Pharmacol Ther 2017;44:38-45.

13 Lai T, Wang S, Xu Z, et al: Long-term efficacy and safety of omalizumab in patients with persistent uncontrolled allergic asthma: a systematic review and meta-analysis. Sci Rep 2015;5:8191.

14 Tzortzaki EG, Georgiou A, Kampas D, et al: Long-term omalizumab treatment in severe allergic asthma: the South-Eastern Mediterranean "real-life" experience. Pulm Pharmacol Ther 2012;25:77-82.

-15 Zazzali JL, Raimundo KP, Trzaskoma B, et al: Changes in asthma control, work productivity, and impairment with omalizumab: 5-year EXCELS study results. Allergy Asthma Proc 2015;36:283-292.

16 Menzella F, Facciolongo N, Piro R, et al: Clinical and pharmacoeconomic aspects of omalizumab: a 4-year follow-up. Ther Adv Respir Dis 2012;6:87-95.
17 Pace E, Ferraro M, Bruno A, et al: Clinical benefits of 7 years of treatment with omalizumab in severe uncontrolled asthmatics. J Asthma 2011;48:387-392.

18 Ozgur ES, Ozge C, Ilvan A, et al: Assessment of long-term omalizumab treatment in patients with severe allergic asthma long-term omalizumab treatment in severe asthma. J Asthma 2013;50:687-694.

19 Storms W, Bowdish MS, Farrar JR: Omalizumab and asthma control in patients with moderate-to-severe allergic asthma: a 6-year pragmatic data review. Allergy Asthma Proc 2012;33:172-177.

20 Luu M, Bardou M, Bonniaud P, et al: Pharmacokinetics, pharmacodynamics and clinical efficacy of omalizumab for the treatment of asthma. Expert Opin Drug Metab Toxicol 2016;12:1503-1511.

21 Xolair $^{\circledR}$ [package insert]. Basel, Novartis Pharma AG, 2014.

22 Bousquet JS, R. Volkan, M: Global evaluation of treatment effectiveness (GETE) is an accurate predictor of response to omalizumab in patients with severe allergic asthma: a pooled analysis. Eur Respir J 2014;44:3483.

23 Barnes N, Menzies-Gow A, Mansur AH, et al: Effectiveness of omalizumab in severe allergic asthma: a retrospective UK real-world study. J Asthma 2013;50:529-536.
24 Braunstahl GJ, Chlumsky J, Peachey G, et al: Reduction in oral corticosteroid use in patients receiving omalizumab for allergic asthma in the real-world setting. Allergy Asthma Clin Immunol 2013;9:47.

25 Thomson NC, Chaudhuri R: Omalizumab: clinical use for the management of asthma Clin Med Insights Circ Respir Pulm Med 2012;6:27-40.

26 Vieira T, de Oliveira JF, da Graca CastelBranco M: Short and long-term quality of life and asthma control with omalizumab therapy in a real life setting in Portugal. Allergol Immunopathol (Madr) 2014;42:3-10.

27 Novelli F, Latorre M, Vergura L, et al: Asthma control in severe asthmatics under treatment with omalizumab: a cross-sectional observational study in Italy. Pulm Pharmacol Ther 2015;31:123-129.

28 Gouder C, West LM, Montefort S: The reallife clinical effects of 52 weeks of omalizumab therapy for severe persistent allergic asthma. Int J Clin Pharm 2015;37:36-43.

29 Cazzola M, Camiciottoli G, Bonavia M, et al: Italian real-life experience of omalizumab. Respir Med 2010;104:1410-1416.

30 Caminati M, Senna G, Stefanizzi G, et al Drop-out rate among patients treated with omalizumab for severe asthma: literature review and real-life experience. BMC Pulm Med 2016;16:128. 